\title{
Web-Based Excellent Internship System (EIS) as Interconnected Media to Maintain Student Capabilities During Pandemic Era
}

\author{
Dhika Maha Putri, Sheila Febriani Putri, Dwi \\ Narullia*, Fitri Purnamasari \\ Faculty of Economics \\ Universitas Negeri Malang \\ Malang, Indonesia \\ *dwi.narullia.fe@um.ac.id
}

\author{
Mohd. Rizal Palil \\ Faculty of Economics and Management \\ Universiti Kebangsaan Malaysia \\ Selangor, Malaysia
}

\begin{abstract}
The use of technology to facilitate educational activities amid the Covid-19 pandemic era is becoming an urgency in the academic world today. This is intended so that the teaching and learning process remains conducive, including the process of internship activities that must be followed by students. Continuing our previous studies to build a more modern and suitable internship program, we build an internship system called Excellent Internship System (EIS). This internship system is based on a website platform that can be adopted in higher education institutions. The platform has been developed through the Research and Development (R\&D) method with five IT and education experts, as well as thirty students who have taken internships during the Covid-19 pandemic in 2020. The EIS platform was developed by considering user-friendly aspects, easy access for lecturers, students, and even the institutions where internships were hosted, therefore it is also could be the supportive facility for the internships process.
\end{abstract}

Keywords-Learning methods, technology usage, accounting students, new normal living, Covid-19 pandemic

\section{INTRODUCTION}

The internship is a program provided in the higher education curriculum to improve students' mental skills and readiness to work $[1,2]$. The internship program helps universities to collaborate with industry and also provides opportunities for students to study collaboratively in a real work environment [3]. In this internship program, students will have the opportunity to apply the lessons they get in-class lectures. Students will be able to learn both theory and practice to develop professional skills when carrying out this internship [4]. Furthermore, the internship program is expected to prepare students personally who are ready to enter the world of work.

The internship program is a means for students to learn about different situations and conditions in the school environment and work environment [3]. During this pandemic, it cannot be denied that all learning activities in all educational institutions have been disrupted. All learning activities can no longer be carried out face-to-face. With this obstacle, the implementation of the internship program is also disrupted. Communication, which is usually carried out directly between students and the university, is limited in distance, thus increasing the possibility of delays in information delivery.

Today, the world is trying to deal with the impact and fight Covid-19. So far, the use of advanced technologies such as Machine Learning and Artificial Intelligence is also considered as one of the ways employed by various healthcare providers [5]. Not only in the health sector, but the use of technology is also maximized to facilitate teaching and learning activities. This is also one of the impacts of new normal life to break the spread of the Covid-19 pandemic. The era of new normal life that is currently being promoted also requires the use of technology platforms that are more innovative and userfriendly. To facilitate the implementation of the internship to be able to provide maximum benefits for students, especially during the current new normal era, the role of technology is needed.

This pandemic condition forces the academic community to make adjustments with the help of technology. The role of technology to bridge face-to-face limitations during a pandemic becomes very crucial, including in the implementation of the internship program. Several studies have shown that websites are designed as a means to solve communication problems and replace classroom facilities with distance learning [6-8]. Both students and lecturers in higher education levels are required to get used to using web-based platforms to share their knowledge, both during regular teaching and learning activities, or when they need to mentor the students who participate in internship programs.

One of the technologies that can help implement the internship program is the internship website. The website is already very familiar and popular used to implement distance learning $[6,9,10]$. This internship website is expected to be a centre for information and communication facilities between 
students and universities as the organizer of the internship program. With the advancement of modern technology, the use of the website provides a means for students to be able to continue to carry out the internship process to the full, provide guidance without having to face-to-face, and obtain the latest information in real-time. This study aims to present the website platform design as a medium for implementing a whole series of technology-based internship programs. This study aims to help solve the problems in every stage of the internship program from initial registration to the submission of the final report.

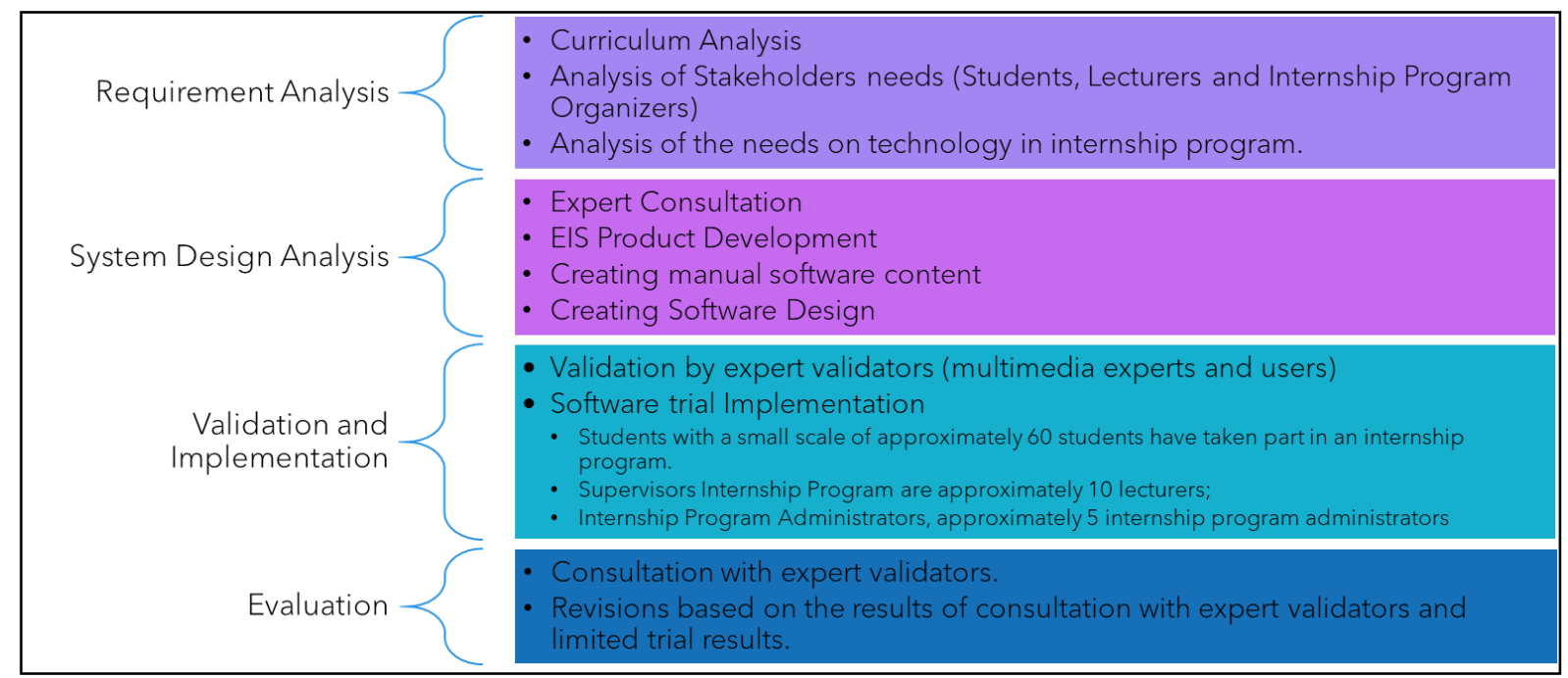

Fig. 1. Research method.

\section{RESEARCH METHODS}

We were conducting the research when the students were taking their internship time during the Covid-19 pandemic era. Specifically, the implementation time is June-August 2020. The timing is considered very appropriate because the Covid19 pandemic demands maximizing technology adoption for the process of mentoring internships.

We use Research and Development (R\&D) method adopted from Borg \& Gall [11] to build EIS (Excellent Internship System), a web-based platform according to our previous analysis on the effective internship system. The details for the research method in this study are illustrated in Figure 1.

\section{RESULTS AND DISCUSSION}

The use of technology to implement education has been widely used, but the use of websites specifically to support the internship program is still not common [3]. In this study, we built a website intended to support the implementation of the internship program, especially now that the world is in a pandemic condition. The development of the internship information system supported by a website is expected to produce a better and more structured internship system. The website-based internship information system in this study is called the Excellent Internship System (EI System), which is expected to minimize problems that arise in managing the internship program

\section{A. Website Display}

We chose the website as the EIS platform which will be a place where students, supervisors, and companies where internships can interact. This internship website is expected to be a center for information and communication facilities between students and universities as the organizer of the internship program.

We designed the website by including the identity of the students' college, starting with the selection of the appearance, domain, contact address that can be accessed by all users if they need correspondence. Figure 2 shows the graphic inclusion and university identity on the website homepage.

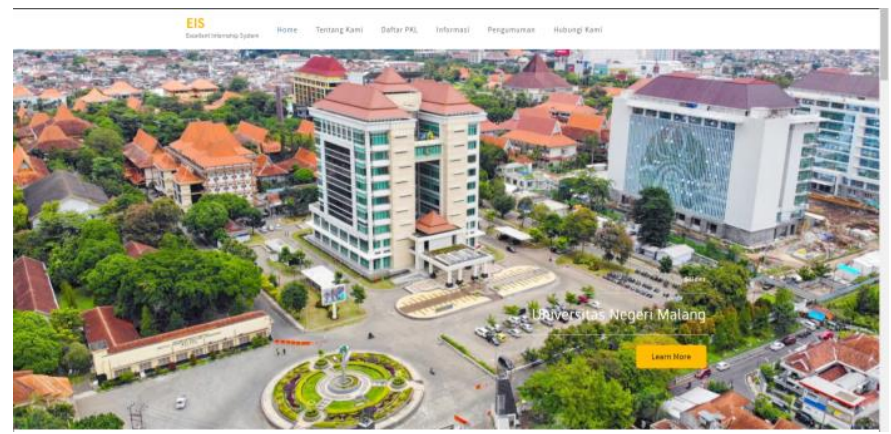

Fig. 2. University identity on homepage.

To clarify the designation of this website, we also include a profile of the vision and mission as well as the objectives of the 
internship activities. The depiction of this section is in Figure 3. Of course, this section can also be adjusted according to the internship activity profile according to the college that uses it. In addition, students can access various announcements and internship activity guides on this website page. The EIS platform is also expected to meet students' needs for information related to internships more quickly. Usually, internship announcements are given on the department's announcement board or department website, which allows delays in delivering information to students because they are piled up with other information updates. On this website, it is hoped that students can obtain information related to internships promptly (Figure 4).

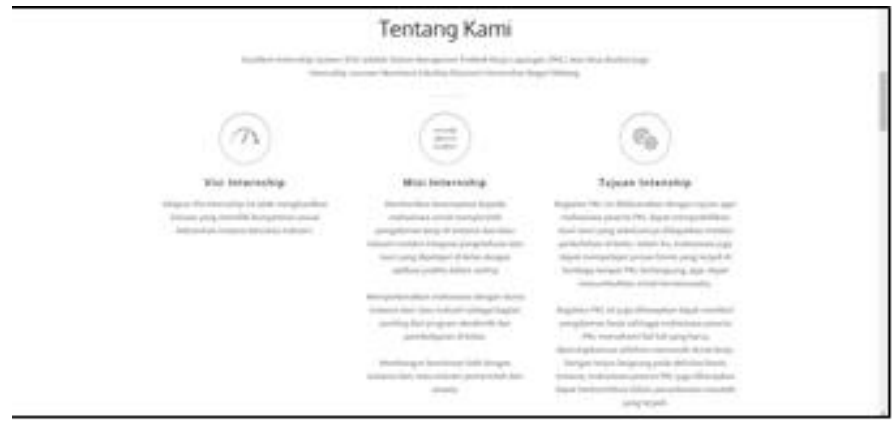

Fig. 3. EIS profile.

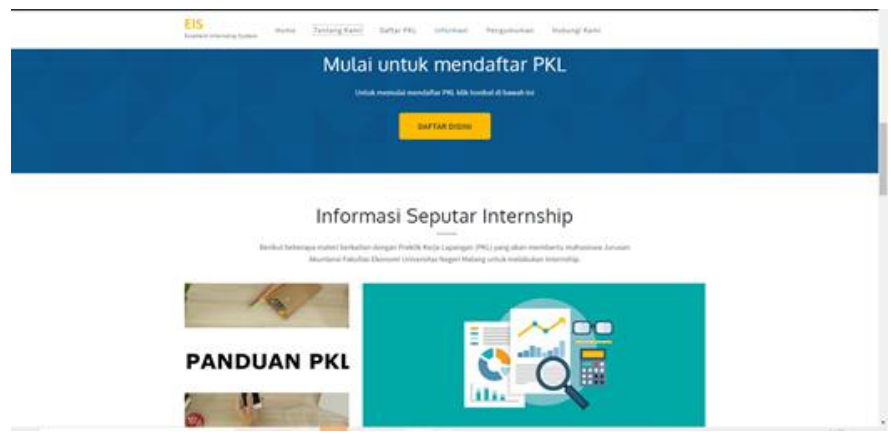

Fig. 4. Information page.

On this information page, there is also information related to the cooperation of University with companies and industries. The most common problem in the internship program is the difficulty in placing students, which allows students to be placed in divisions that are not in accordance with their field of expertise $[1,3]$. Therefore, there is a need for cooperation between universities and companies. Internship collaboration carried out by universities and companies can help students to get internship placements that are in accordance with their areas of expertise [12]. The information page in EIS platform also provides a page showing which companies have collaborated with the university (Figure 5).

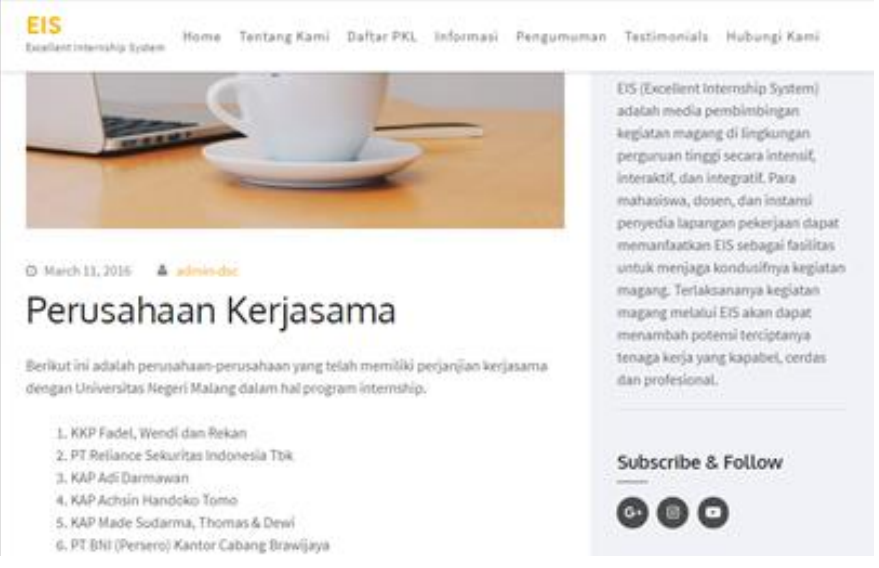

Fig. 5. Information page.

The EIS website also lists several company names that have collaborated with the university. This collaboration is about the admission of students as internal staff for a certain period. Students can process applications for internships at these companies through this website. Then, the faculty/university can approve the submission on the recommendation of each student's supervisor. Of course, all these processes will be passed after students register/input their personal data on the registration page (Figure 6).

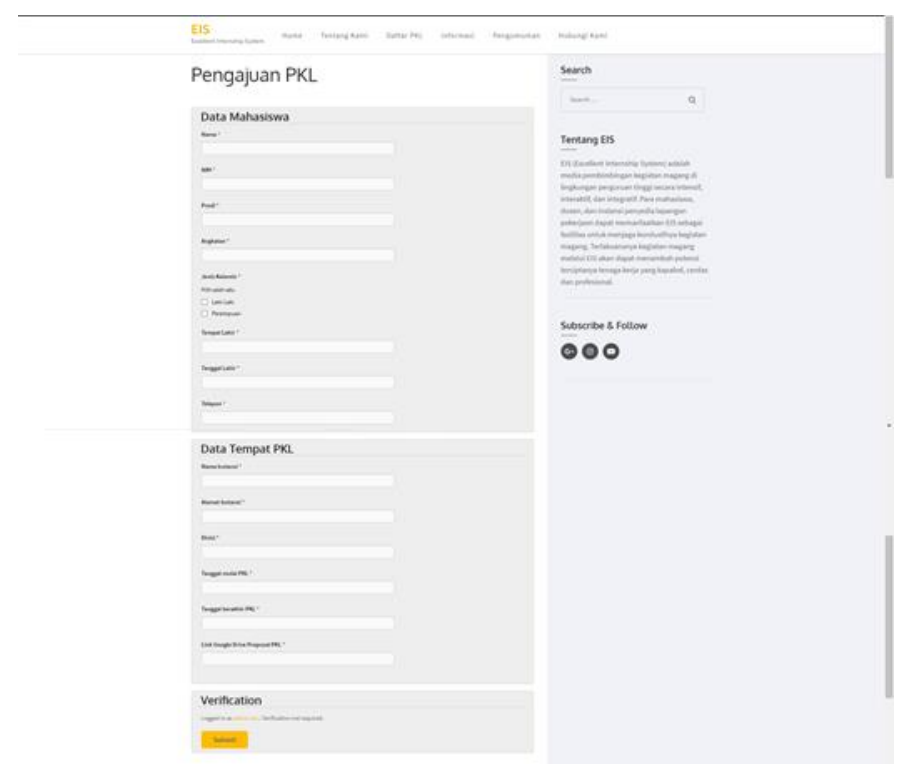

Fig. 6. Registration page.

If a student has received approval to take part in internship activities at a company, he or she can then follow the mentoring process from the lecturer through this website. During several mentoring meetings, lecturers can provide material on the urgency of soft skills and hard skills when entering the world of work, as well as two-way discussions with students about impressions and constraints during 
internship activities. The material to be given to students can of course be uploaded on the website.

The mentoring process by lecturers is also carried out when students want to consult about the preparation of reports on the results of internship activities. Students can upload a draft of the report, to be given suggestions and criticism by the lecturer. Furthermore, the reports that have gone through the review process can also be accessed again by students.

Some of the features offered by EIS are interactive and comprehensive facilities which are expected to be interconnected media to accommodate the needs of synchronous or asynchronous online internship guidance. A system like this is the answer to communication needs during the Covid-19 pandemic era, where direct physical contact is very limited.

\section{B. Product's Validation from IT Experts}

Based on the IT expert questionnaire results, the Excellent Internship System (EIS) as a medium for implementing a technological-based internship obtained a $98.33 \%$ score. The questionnaire results said that EIS is valid and feasible to be used as an internship platform.

The qualitative result noted that, in general, this website does not require too much revision. In conclusion, the website succeeded in providing understanding related to the internship process. Besides, we obtain that the majority of validators commented that the EIS is systematic, traceable, and the logical flow is clear and may reduce the ineffective access times for internship procedure.

We have also conducted some trials as the alternative evaluation steps on building the EIS website. We selected 30 students who received an obligation from their respective campuses to take part in internship activities during the pandemic period. During a period of 1-2 hours, students are given time to access, ask questions, suggestions and criticize the EIS website, so that in the end they can provide an assessment of the EIS. Based on the trial data, the score or the total number was 85\%, which means the Website Excellent Internship System (EIS) is valid and suitable for being used as an internship platform.

\section{CONCLUSION}

The method used in this EIS Website development is Instructional Development Institute (IDI) from R\&D method which consists of 4 steps, Requirement Analysis, System Design Analysis, Validation and Implementation, and Evaluation. Based on the results of the validation carried out by internship and IT experts, it can be concluded that the EIS Website is valid. In general, this website does not require too much revision. Based on the trial data from students, the Website Excellent Internship System (EIS) is valid and suitable for being used as an internship platform. The results of the research and validation show that the Excellent Internship System can be used to support the implementation of the internship program.

\section{ACKNOWLEDGMENT}

We thank LP2M Universitas Negeri Malang and all EIS validators so that this research can be carried out well.

\section{REFERENCES}

[1] S. F. Putri, D. M. Putri, F. Purnamasari, M. Puspaningtyas, and D. Narullia, "Composing Professional Human Resource: The Necessity of Excellent Internship Mentoring System," in International Conference on Economics, Business and Economic Education (ICE-BEES), 2019.

[2] D. M. Putri, D. Narullia, S. F. Putri, F. Purnamasari, M. Puspaningtyas, and M. R. Palil, "Towards the Qualified Human Resource: Internship Program at Leading Ex-LPTK Universities in Indonesia," Proc. 3rd Asia Pacific Manag. Res. Conf. (APMRC 2019) Towar., vol. 149, pp. 97101, 2020.

[3] Y. Yannuar, B. Hasan, A. G. Abdullah, D. L. Hakim, and D. Wahyudin, "Design and implementation of web-based internship information system at vocational school," IOP Conf. Ser. Mater. Sci. Eng., vol. 434, no. 1,2018

[4] L.-J. ChanLin and W.-H. Hung, "Evaluation of An Online Internship Journal System for Interns," Procedia - Soc. Behav. Sci., vol. 191, pp. 1024-1027, 2015

[5] Lalmuanawma, J. Hussain, and L. Chhakchhuak, "Applications of machine learning and artificial intelligence for Covid-19 (SARS-CoV-2) pandemic: A review," Chaos, Solitons and Fractals, vol. 139, p. 110059, 2020 .

[6] M. L. Buffington, "Blogging with graduate students," Distance Learn., vol. 4, no. 1, pp. 21-27, 2007.

[7] N. B. Ellison and Y. Wu, "Blogging in the Classroom: A Preliminary Exploration of Student Attitudes and Impact on Comprehension," J Educ Multimed. Hypermedia, vol. 17, no. 1, pp. 99-122, 2008.

[8] S. Glogoff, "Instructional blogging: Promoting interactivity, studentcentered learning, and peer input," Innov. J. Online Educ., vol. 1, no. Exhibit 1, pp. 2002-2005, 2005.

[9] D. Churchill, "Educational applications of Web 2.0: Using blogs to support teaching and learning: Original Articles," Br. J. Educ. Technol., vol. 40, no. 1, pp. 179-183, 2009.

[10] S. Downes, "Educational Blogging," J. Mark. Educ., vol. 32, no. 1, pp. 50-63, 2010.

[11] W. Borg and M. Gall, Educational research: An introduction (4th ed.). White Plains, NY: Longman. 1983

[12] N. Hasti, S. Lesari, and I. Gustiana, "Web-Based Internship Information System," IOP Conf. Ser. Mater. Sci. Eng., vol. 662, no. 2, 2019. 